\title{
Diminished creatinine clearance in anorexia nervosa: reversal with weight gain
}

\author{
F BOAG, J WEERAKOON, J GINSBURG, CWH HAVARD, P DANDONA \\ From the Endocrine and Metabolic Units (Chemical Pathology), Royal Free Hospital and School of \\ Medicine, London
}

SUMMARY To assess whether patients with anorexia nervosa have abnormalities in creatinine clearance, we measured plasma creatinine concentration, urinary creatinine excretion, and creatinine clearance in 10 patients with anorexia nervosa before and during treatment. Urinary creatinine excretion and creatinine clearance were diminished in all patients. Nine patients had significant decreases in their plasma creatinine and creatinine clearance was increased even when corrected for body weight and body surface area respectively. The patient who did not show these changes in plasma creatinine concentration and creatinine clearance had gained only $4 \%$ in body weight. Body weight and corrected creatinine clearance were significantly correlated, as were percentage increases in body weight and creatinine clearance. Thus anorexia nervosa is associated with a reversible decrease in creatinine clearance. Increase in body weight appears to be cardinal to the recovery of renal function in these patients.

Patients with anorexia nervosa have a considerable reduction in muscle bulk, and since the main source of creatinine in the body is from creatine, which is metabolised by muscle, ${ }^{\prime}$ it is likely that creatinine turnover in such patients would be reduced. Low protein diets are also associated with a small reduction in creatinine clearance in normal subjects. ${ }^{2} \mathrm{We}$ therefore set out to determine whether patients with anorexia nervosa had any abnormalities in their plasma creatinine concentrations, urinary creatinine excretion, or creatinine clearance.

\section{Patients and methods}

Ten female patients with anorexia nervosa were included in this study. All patients were more than $30 \%$ below the mean body weight for height, had secondary amenorrhoea and lanugo hair, avoided food, and had disturbances of their body image. Investigations showed no other cause of weight loss. All patients were admitted to the metabolic ward for investigations and treatment. The treatment consisted of initial bed rest, a high calorie $(3500 \mathrm{kcal})$ and high protein diet, supportive therapy, and monitoring of fluid input and output. The patients were not allowed to leave the ward at any time. None of the patients was clinically dehydrated: their skin turgor was normal, the mucosae moist, and there was no postural hypotension.

Accepted for publication 24 September 1984
Measurement of creatinine clearance was started $48 \mathrm{~h}$ after admission. During this period the patients were allowed a free fluid intake. Twenty four hour urine collections were started at 8.00 am and completed at 8.00 am the following day, when venous blood samples were obtained for plasma creatinine estimation. Albumin, protein, urea, electrolyte, and creatinine concentrations in plasma samples were measured by a SMAC Technicon autoanalyser. Urinary creatinine concentration was measured by the alkaline picrate method on a Technicon autoanalyser.

Creatinine clearance was calculated from plasma and urinary urea using the formula $U V / P$, where $U$ $=$ urinary creatinine concentration, $\mathrm{V}=$ urine volume, $\mathbf{P}=$ plasma creatinine concentration. Plasma creatinine concentration, urine creatinine excretion, and creatinine clearance were corrected to a body weight of $60 \mathrm{~kg}$. Statistical analysis was carried out by Mann-Whitney and Student's $t$ tests and Spearman coefficient of rank correlation.

After between 10 and 58 days of dietary treatment, the urine and plasma collections were repeated. In patients $1,2,4$, and 6 serial measurements of all indices were carried out.

\section{Results}

All patients included in this study had body weights which were $36 \%$ (median) (range 18-46\%) below the ideal weight for their height. All patients except 
one increased in weight by at least $10 \%$ during their stay in the hospital. The median weight increase during the creatinine clearance study was $18 \%$ (range $4 \cdot 1-42 \%$ ) (Table 1$)$.

The mean packed cell volume on admission was $40 \%$, while that on discharge was $38 \%$. The mean (SD) total plasma protein and albumin concentrations on admission were $67 \cdot 6(7 \cdot 5)$ and $42 \cdot 5(2 \cdot 8) \mathrm{g} / \mathrm{l}$ and did not alter significantly while patients were in hospital: $68.3(4.4)$ and $42.9(2.9) \mathrm{g} / 1$ respectively.

Plasma urea concentrations were not significantly altered following treatment: mean values (SD) before and after treatment were $5.6(2.5)$ and 5.2 (1.9) $\mathrm{mmol} / \mathrm{l}$ respectively. The median plasma sodium concentration on admission was $140 \mathrm{mmol} / \mathrm{l}$ (range 131-142 mmol/l), while that at the end of treatment was $140 \mathrm{mmol} / \mathrm{l}$ (range $138-143 \mathrm{mmol} / \mathrm{l}$ ). The only appreciable electrolyte abnormality was that three of these patients had subnormal plasma potassium concentrations. But the median concentration for the entire group was $3.9 \mathrm{mmol} / \mathrm{l}$ (range $1.7-4.5 \mathrm{mmol} / \mathrm{l})$ and was similar to that after treatment (median $3.9 \mathrm{mmol} / \mathrm{l}$; range $3.2-4.8 \mathrm{mmol} / \mathrm{l}$ ) without specific supplementation with potassium. Patient 3 had plasma sodium and potassium concentrations of $131 \mathrm{mmol} / \mathrm{l}$ and $1.7 \mathrm{mmol} / \mathrm{l}$ respectively.

Twenty four hour urinary output increased significantly while the patients were in hospital from a median of $1169 \mathrm{ml}$ to $1800 \mathrm{ml}$ (Table 2). During the $48 \mathrm{~h}$ period before these collections, the median $24 \mathrm{~h}$ fluid intake was $1450 \mathrm{ml}$ and urine output was $980 \mathrm{ml}$. The overall fluid balance in these patients during their stay in hospital ranged between -2.7 and $+3 \cdot 2$ litres (Table 1 ).

Plasma creatinine concentration corrected for body weight decreased in all patients except patient 10 , who gained only $4 \%$ in body weight. This decrease in corrected plasma creatinine concentration was partly the result of an increase in body weight, since the mean uncorrected plasma
Table 2 Patients' 24 h urinary output, plasma and urinary creatinine concentrations, and creatinine clearance before and after treatment

\begin{tabular}{lll}
\hline & Before & After \\
\hline 24 h urinary output & 1169 & $* 1800$ \\
(ml) & $(490-1640)$ & $(570-2280)$ \\
Plasma creatinine & 74 & 64 \\
concentration $(\mu \mathrm{mol} / \mathrm{l})$ & $(61-95)$ & $(47-127)$ \\
Urinary creatinine & $4 \cdot 7$ & $8 \cdot 2$ \\
concentration $(\mathrm{mmol} / \mathrm{l})$ & $(3-6 \cdot 8)$ & $(6 \cdot 8-9 \cdot 3)$ \\
Creatinine clearance & 50 & $* 90$ \\
(ml/min) & $(34-59)$ & $(51-103)$ \\
\hline
\end{tabular}

Values given as median (range).

${ }^{*} \mathrm{p}<0.01$.

creatinine concentration, though lower after treatment, did not fall significantly (Table 2). Mean urinary creatinine output increased considerably (from 4.7 to $7.99 \mathrm{mmol} / 24 \mathrm{~h}$ ), with individual increases occurring in all except one patient (Table 2). Only two patients ( 2 and 3 ) showed significant decreases in plasma urea concentrations following weight increase; these two patients also had the greatest falls in their plasma creatinine concentrations. Thus these two probably had an element of prerenal uraemia.

The mean corrected creatinine clearance increased significantly (Table 1 and Fig. 1), with substantial increases in all patients who gained weight except patient 10 . Creatinine clearance values, uncorrected for weight, also increased substantially in all patients except patient 10 . There was a significant correlation between weight gain and corrected $(r=0.8 ; p<0.01)$ and uncorrected $(r=0.8$; $\mathrm{p}<0.01)$ creatinine clearance. There was also a correlation between percentage body weight and percentage increase in creatinine clearance $(r=0.6$; $\mathrm{p}<0.05)$.

In four patients creatinine clearance was measured sequentially during the days after admission. Substantial increases were seen within four to five days and, at least in two patients, even before

Table 1 Patients' weight, overall fuid balance, corrected plasma and urine creatinine concentrations and corrected creatinine clearance and plasma urea concentrations before $(B)$ and after $(A)$ treatment

\begin{tabular}{|c|c|c|c|c|c|c|c|c|c|c|c|c|c|}
\hline \multirow[t]{3}{*}{ Patient } & \multirow{3}{*}{$\begin{array}{l}\text { No days } \\
\text { treatment }\end{array}$} & \multicolumn{2}{|c|}{ Weight (kg) } & \multirow{3}{*}{$\begin{array}{l}\% \\
\text { increase }\end{array}$} & \multirow{3}{*}{$\begin{array}{l}\text { Fluid } \\
\text { balance }(l)\end{array}$} & \multirow{2}{*}{\multicolumn{2}{|c|}{ 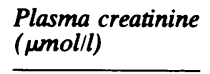 }} & \multirow{2}{*}{\multicolumn{2}{|c|}{$\begin{array}{l}\text { Urine creatinine } \\
(\mathrm{mmol} / 24 \mathrm{~h})\end{array}$}} & \multirow{2}{*}{\multicolumn{2}{|c|}{$\begin{array}{l}\text { Creatinine clearance } \\
\text { (ml/min) }\end{array}$}} & \multirow{2}{*}{\multicolumn{2}{|c|}{$\begin{array}{l}\text { Plasma urea } \\
\text { (mmol/l) }\end{array}$}} \\
\hline & & $B$ & $\boldsymbol{A}$ & & & & & & & & & & \\
\hline & & & & & & $\boldsymbol{B}$ & $\boldsymbol{A}$ & $\boldsymbol{B}$ & $\boldsymbol{A}$ & $\boldsymbol{B}$ & $\boldsymbol{A}$ & $\boldsymbol{B}$ & $A$ \\
\hline $\begin{array}{r}1 \\
2 \\
3 \\
4 \\
5 \\
6 \\
7 \\
8 \\
9 \\
10\end{array}$ & $\begin{array}{l}58 \\
17 \\
13 \\
17 \\
10 \\
25 \\
31 \\
15 \\
28 \\
14\end{array}$ & $\begin{array}{l}32 \\
33 \cdot 4 \\
35 \cdot 2 \\
44 \cdot 6 \\
32.6 \\
33.7 \\
31 \\
29.9 \\
37 \cdot 8 \\
43 \cdot 2\end{array}$ & $\begin{array}{l}40.2 \\
39 \\
44 \cdot 2 \\
49 \cdot 7 \\
36 \cdot 8 \\
40 \cdot 2 \\
44 \cdot 2 \\
36 \cdot 9 \\
41 \cdot 8 \\
45\end{array}$ & $\begin{array}{l}25 \cdot 6 \\
18 \\
26 \\
11 \cdot 4 \\
12 \\
19 \cdot 2 \\
42 \\
.23 \\
11 \\
4 \cdot 1\end{array}$ & $\begin{array}{l}+3.2 \\
-2.7 \\
-1.4 \\
+0.8\end{array}$ & $\begin{array}{l}126 \\
164 \\
114 \\
106 \\
136 \\
139 \\
118 \\
182 \\
155 \\
131\end{array}$ & $\begin{array}{r}90 \\
72 \\
68 \\
71 \\
104 \\
101 \\
90 \\
132 \\
103 \\
140\end{array}$ & $\begin{array}{r}10.7 \\
8.4 \\
6.1 \\
8.6 \\
11 \\
8.2 \\
5.8 \\
7.5 \\
11.6 \\
9.4\end{array}$ & $\begin{array}{r}12.8 \\
12.6 \\
4.9 \\
10.4 \\
12.5 \\
14.8 \\
13.3 \\
13.3 \\
11.5 \\
9.8\end{array}$ & $\begin{array}{l}83 \\
47 \cdot 5 \\
49 \\
69 \\
76 \\
53 \\
44 \\
37 \\
79 \\
60 \cdot 5\end{array}$ & $\begin{array}{r}122 \\
150 \\
59 \\
110 \\
105 \\
123 \\
117 \\
88 \\
107 \\
59\end{array}$ & $\begin{array}{r}4.9 \\
11.4 \\
7.6 \\
2.4 \\
3.1 \\
6.6 \\
4.9 \\
5.8 \\
5.1 \\
4.5\end{array}$ & $\begin{array}{l}6 \cdot 3 \\
3 \cdot 0 \\
2 \cdot 9 \\
4 \cdot 6 \\
5 \cdot 2 \\
6 \cdot 7 \\
4 \cdot 8 \\
6 \cdot 8 \\
7 \cdot 1 \\
4 \cdot 8\end{array}$ \\
\hline
\end{tabular}

Complete fluid balance data were not available for patients $4,6,7$, and 8 . 
significant increases in weight began to occur (Figs. 2 and 3 ).

\section{Discussion}

Our data show clearly that the turnover of creatinine increased substantially after the institution of high protein and high calorie diets in the nine patients with significant weight gains. This is reflected in the $56 \%$ increase in urinary creatinine excretion,
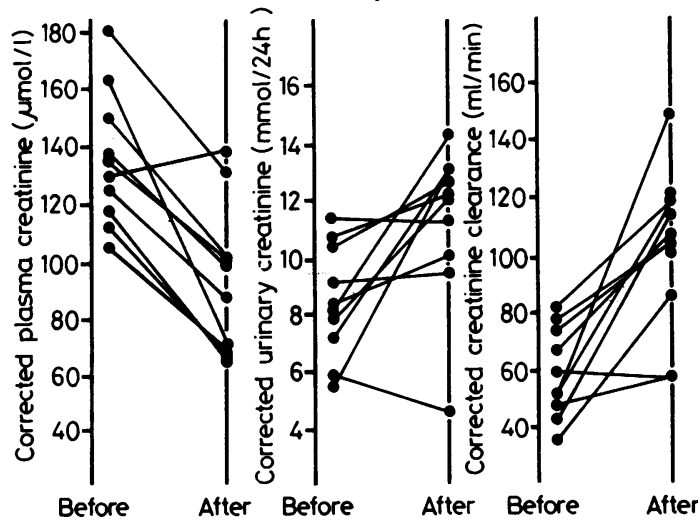

Treatment

Fig. 1 Corrected plasma creatinine, urinary creatinine, and creatinine clearance in patients with anorexia nervosa before and after treatment. $p<0.01$ for all these indices when patient 10, who did not respond to treatment, is excluded.

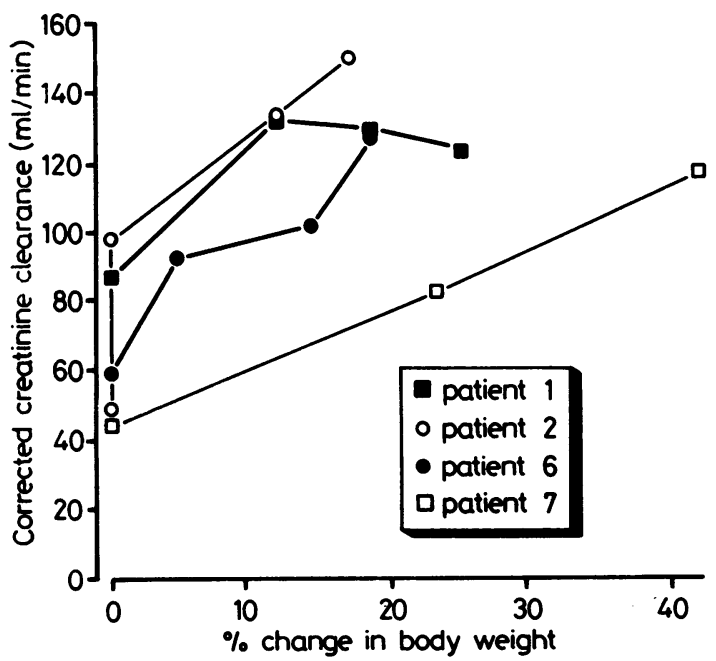

Fig. 2 Increase in corrected creatinine clearance in association with percentage change in body weight.

associated with an $18 \%$ increase in body weight. The increase in urinary creatinine is significant even when corrected for body weight. The magnitude of this increase in creatinine excretion is substantially

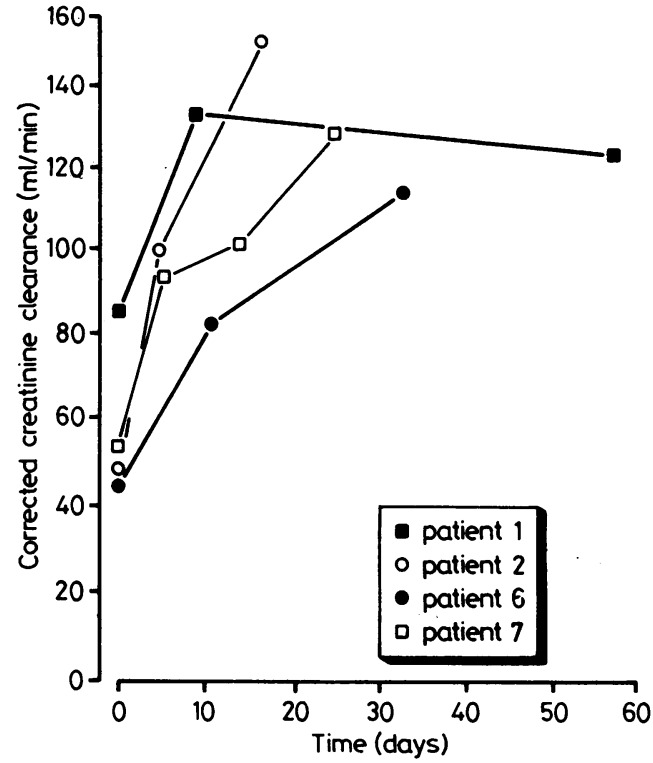

Fig. 3 Increase in corrected creatinine clearance in association with duration of treatment.

greater than the $10 \%$ increase reported in normal subjects who were fed on $0.5 \mathrm{~g} / \mathrm{kg}$ protein intake for a period followed by an intake of $2.5 \mathrm{~g} / \mathrm{kg}^{2}$ The mechanism underlying the increase in creatinine turnover and excretion is unlikely to be a mere increase in protein intake. An increase in muscle bulk and the enhancement of metabolism of creatine by muscle may therefore contribute significantly to the increased urinary excretion of creatinine.

The more intriguing aspect of our data in all of the nine patients who gained more than $10 \%$ of their body weight is the fall in plasma creatinine concentration and the increase in creatinine clearance (corrected for body weight). This considerable increase in creatinine clearance associated with a fall in plasma creatinine is not the consequence of prior dehydration or prerenal uraemia, since collections of urine and blood samples were started after $48 \mathrm{~h}$ of admission. During this $48 \mathrm{~h}$ period the patients were on free fluid intake (median $1450 \mathrm{ml} / 24 \mathrm{~h}$ ), had reasonable urinary output (median $890 \mathrm{ml} / 24 \mathrm{~h}$ ), and did not have clinical evidence of dehydration. None of the patients showed either haemoconcentration at the time of admission or a subsequent fall in packed cell volume with an increase in weight; nor were there increases in plasma protein or albumin concentrations. Plasma urea concentrations did not alter in a systematic manner, with some increasing and others decreasing. These facts, as well as the observations that the patients followed longitudinally had steady and continuous increases in 
creatinine clearance as they increased in weight over several weeks, suggests that this increase is not merely a correction of hypovolaemia and early prerenal uraemia. Finally, preliminary studies on the measurements of plasma volume in such patients do not confirm appreciable hypovolaemia (Wakeling, personal communication).

The fall in plasma creatinine and the increase in urinary creatinine and creatinine clearance were associated with increases in the weights of the patients; there was also a correlation between the percentage increase in weight and percentage increase in the creatinine clearance indices. This implies that an increase in muscle mass would account to a large extent for the enhanced creatinine production and creatinine clearance. Other factors may also contribute to the changes in these indices.

Among the other mechanisms which may influence creatinine clearance in patients with anorexia nervosa is renal vasoconstriction. These patients have vasospastic phenomena like Raynaud's syndrome associated with hypersensitivity to nor-adrenaline ${ }^{3}$ and a pronounced increase in platelet aggregability ${ }^{4}$ and thromboxane release. ${ }^{5}$ Abnormalities of vascular reactivity occur in patients with anorexia nervosa. These patients have extremely low cutaneous blood flow and show substantial increases in skin blood flow after meals. ${ }^{6}$ Vascular phenomena related to malnutrition may thus be important in the pathogenesis of low creatinine clearance, glomerular perfusion, and filtration. These changes probably revert to normal after the patients gain weight. Circulatory changes in the kidney also occur with dietary alterations. For example, an increase in protein intake leads to an increase in effective renal plasma flow. ${ }^{2}$ The pronounced rapid increase in creatinine clearance after refeeding but before significant weight increases seen in patients 2 and 6 again point to a vascular mechanism underlying this process.

$A^{\prime}$ diminished ability by these patients to clear water through their kidneys has previously been shown by Russell and Bruce.? They also showed an increase in creatinine clearance in three patients after weight gain; but no data relating to creatinine excretion or correction of creatinine clearance against weight were presented.

We have previously shown that creatinine clearance in vegetarian osteomalacic patients with vitamin $\mathrm{D}$ deficiency is subnormal. ${ }^{8}$ Patients with anorexia nervosa also have marginal or low vitamin D states (unpublished observations) and this may contribute to the low creatinine clearance in these patients. It should, however, be noted that osteomalacic patients have paradoxical subnormal plasma creatinine values in association with sub- normal creatinine clearance before treatment; this contrasts with anorectic patients, in whom corrected plasma creatinine concentrations fall significantly after treatment. ${ }^{8}$ Furthermore, no significant increase in creatinine clearance or urinary creatinine excretion was noted after vitamin D treatment. ${ }^{9}$

Finally, the diminished creatinine clearance in these patients may be due to mild hypovolaemia, which is not sufficient to reach subnormal levels but enough to cause a fall in renal perfusion. The significant falls in plasma urea and the substantial falls in plasma creatinine concentrations in patients 2 and 3 would indicate that this mechanism may be operative in them. Sequential measurements of plasma volume and renal blood flow after treatment may elucidate this aspect further.

In conclusion, patients with anorexia nervosa have considerably diminished urinary creatinine excretion and creatinine clearance. After the institution of a refeeding regimen and an increase in weight, both urinary creatinine excretion and creatinine clearance become normal. This is the first demonstration that changes in body weight and dietary intake may have profound effects on creatinine related indices of renal function. Such changes may be relevant to patients with malnutrition due to other causes. Whereas the mechanisms underlying these changes are under investigation at this moment, the impairment of renal function in this condition is reversible. Treatment of weight loss should be the mainstay of management rather than invasive nephrological investigation.

\section{References}

' Doolan PD, Alpen EL, Trill GB. A clinical appraisal of the plasma concentration and endogenous clearance of creatinine. Am J Med 1962;32:65-79.

${ }^{2}$ Farrington K, El Nahas AM, Hibon AJW, Gornacz G, Bloom SR, Moorhead JF. Gut hormones and glomerular hyperfiltration. Lancet 1984; i: 636.

${ }^{3}$ Luck P, Wakeling A. Increased cutaneous vasoreactivity to cold in anorexia nervosa. Clin Sci 1981;61:659-67.

4 Luck P, Mikhailidis DP, Dashwood MR, et al. Platelet hyperagregability and increased $\alpha$-adrenoceptor density in anorexia nervosa. J Clin Endocrinol 1983;57:911-4.

5 Mikhailidis DP, Barradas MA, De Souza V, et al. Platelet function in anorexia nervosa. J Psychiat Res (in press).

' Luck P, Wakeling A. Altered thresholds for thermoregulatory sweating and vasodilatation in anorexia nervosa. $\mathrm{Br}$ Med J 1980;281:906-8.

' Russell GFM, Bruce JT. Impaired water diuresis in patients with anorexia nervosa. Am J Med 1966;40:38-48.

${ }^{8}$ Fonseca V, Mohiuddin J, Weerakoon J, Mikhailidis DP, Boss M, Dandona P. Plasma creatinine and creatinine clearance in nutritional osteomalacia. Lancet 1984;i:1093-5.

Requests for reprints to: Dr P Dandona, Metabolic Unit, Department of Chemical Pathology and Human Metabolism, Royal Free Hospital, London. NW3 2QG, England. 